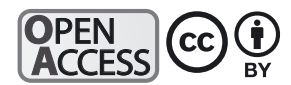

\title{
Assessment of the status and trends in abundance of a coastal pinniped, the Australian sea lion Neophoca cinerea
}

\author{
Simon D. Goldsworthy ${ }^{1,2, *}$, Peter D. Shaughnessy ${ }^{1,3}$, Alice I. Mackay ${ }^{1}$, \\ Frederic Bailleul ${ }^{1}$, Dirk Holman ${ }^{4}$, Andrew D. Lowther ${ }^{5}$, Brad Page ${ }^{6}$, Kelly Waples ${ }^{7}$, \\ Holly Raudino ${ }^{7}$, Simon Bryars ${ }^{8}$, Tim Anderson ${ }^{9}$

\begin{abstract}
${ }^{1}$ South Australian Research and Development Institute, West Beach, South Australia 5024, Australia
${ }^{2}$ School of Biological Sciences, The University of Adelaide, Adelaide, South Australia 5005, Australia

${ }^{3}$ South Australian Museum, North Terrace, Adelaide, South Australia 5000, Australia

${ }^{4}$ Department for Environment and Water, Port Lincoln, South Australia 5066, Australia

${ }^{5}$ Norwegian Polar Institute, Framsentret, 9296 Tromsø, Norway

${ }^{6}$ Department of Primary Industries and Regions, Urrbrae, South Australia 5064, Australia

${ }^{8}$ Department for Environment and Water, Adelaide, South Australia 5000, Australia
\end{abstract} \\ ${ }^{7}$ Department of Biodiversity, Conservation and Attractions, Kensington, Western Australia 6151, Australia \\ ${ }^{9}$ Helifarm, Ceduna, South Australia 5690, Australia
}

\begin{abstract}
Australian sea lions Neophoca cinerea are endemic to Australia, with their contemporary distribution restricted to South Australia (SA) and Western Australia (WA). Monitoring of the species has proved challenging due to prolonged breeding events that occur non-annually and asynchronously across their range. The most recent available data from 80 extant breeding sites (48 in SA, 32 in WA) enabled us to estimate the species-wide pup abundance to be 2739, with $82 \%$ (2246) in SA and 18\% (493) in WA, mostly based on surveys conducted between 2014 and 2019. We evaluated 1776 individual site-surveys undertaken between 1970 and 2019 and identified admissible time-series data from 30 breeding sites, which revealed that pup abundance declined on average by $2.0 \% \mathrm{yr}^{-1}$ (range $9.9 \%$ decline to $1.7 \%$ growth $\mathrm{yr}^{-1}$ ). The overall reduction in pup abundance over 3 generations (42.3 yr) was estimated to be $64 \%$, with over $98 \%$ of Monte Carlo simulations producing a decline $>50 \%$ over a 3-generation period, providing strong evidence that the species meets IUCN 'Endangered' criteria (decline $\geq 50 \%$ and $\leq 80 \%$ ). The population is much smaller than previously estimated and is declining. There is a strong cline in regional abundances (increasing from west to east), with marked within-region heterogeneity in breeding site pup abundances and trends. Results from this study should improve consistency in the assessment of the species and create greater certainty among stakeholders about its conservation status. To facilitate species management and recovery, we prioritise key data gaps and identify factors to improve population monitoring.
\end{abstract}

KEY WORDS: Australian sea lion · Declining population $\cdot$ Endangered species $\cdot$ IUCN Red List Criteria $\cdot$ South Australia $\cdot$ Western Australia

\section{INTRODUCTION}

The global threat to biodiversity has spurred the world's governments to develop a suite of policy initiatives such as the UN Convention on Biological

*Corresponding author: simon.goldsworthy@sa.gov.au
Diversity (CBD) and the Sustainable Development Goals (UN 2019, CBD 2020). Following the recent United Nations Summit on Biodiversity (September 2020), 77 countries signed The Leaders' Pledge for Nature, committing them to reversing biodiversity

() The authors 2021. Open Access under Creative Commons by Attribution Licence. Use, distribution and reproduction are unrestricted. Authors and original publication must be credited. 
loss by 2030 (Leaders' Pledge for Nature 2020). The International Union for the Conservation of Nature (IUCN) Red List represents the largest standardised database of the status, trends and threats to global biodiversity, and provides a critical indicator of the health of the world's biodiversity against which the success of policy initiatives (including those listed above) can be measured (IUCN Standards and Petitions Committee 2019).

Marine mammals have been previously characterised as disproportionally threatened and data poor (Kovacs et al. 2012), with almost one-third of all seal species threatened. Sea lions are 1 of 2 groups of otariid (eared) seals, and comprise 8 taxa (6 species and 2 subspecies) (Committee on Taxonomy 2020). The distribution of these taxa is centred on the Pacific Rim. Globally, sea lions are facing significant conservation and management challenges, with many species in low abundance or facing declines throughout parts or all of their ranges. Sea lions generally forage demersally and mostly occur in near-coastal and continental shelf waters, leaving them vulnerable to increased interactions with human activities such as direct and indirect interactions with fisheries, climate change, extreme weather events (e.g. El Niño), entanglement in marine debris and disease (Kovacs et al. 2012). Given this increased vulnerability, it is unsurprising that the IUCN Red List assesses $75 \%$ of all sea lion taxa at a Near Threatened or higher category (Japanese sea lion Zalophus japonicus: Extinct; Australian sea lion Neophoca cinerea, New Zealand sea lion Phocarctos hookeri, Galapagos sea lion Z. wollebaeki and western Steller sea lion Eumetopias jubatus jubatus: Endangered; eastern Steller sea lion E. j. monteriensis: Near Threatened; Californian sea lion Zalophus californianus and South American sea lion Otaria bryonia: Least Concern). Even for those species listed as Least Concern, some subpopulations have undergone major declines. The Gulf of California subpopulation of $Z$. californianus has undergone a $65 \%$ decline since 1991 (Adame et al. 2020), and the Falkland Islands subpopulation of O. bryonia is estimated to have declined by $95 \%$ since the 1930 s (Thompson et al. 2005, Baylis et al. 2015).

The Australian sea lion (ASL) was subject to sealing in the late $18^{\text {th }}$ and early $19^{\text {th }}$ century, resulting in a reduction in population size and extirpation from locations within and beyond its current range (Ling 1999, Stuart 2018). Its extant breeding distribution is restricted to islands off South Australia (SA) and Western Australia (WA), with the exception of a number of small mainland breeding sites at the base of cliffs. Known threats to species recovery include fisheries interactions (especially bycatch in demersal gillnet and rock lobster fisheries), entanglement in marine debris and disease (Page et al. 2004, Goldsworthy \& Page 2007, Goldsworthy et al. 2010, Hamer et al. 2013, Marcus et al. 2014, 2015).

Unlike all other pinnipeds, ASLs have a non-annual breeding cycle of about 17-18 mo, with the longest gestation period of any pinniped (up to $14 \mathrm{mo}$, Gales \& Costa 1997). Breeding is protracted (4-12 mo in duration, depending on pup production), can occur at any time of the year and is asynchronous across its range (i.e. adjacent breeding sites can breed at different times) (Kirkwood \& Goldsworthy 2013). Mechanisms suggested to maintain asynchronous breeding are thought to be extreme philopatry and population sub-structuring, effectively making most breeding sites closed subpopulations (Campbell et al. 2008b, Lowther et al. 2012).

There is evidence of significant declines in abundance across parts of the ASL's range (Goldsworthy et al. 2015), with total population estimates ranging between 10000 and 15000 (based on multipliers of pup production) (Goldsworthy et al. 2009a, 2015, Shaughnessy et al. 2011). Because of the species' unusual breeding biology, and the unpredictable timing and duration of breeding seasons among breeding sites, there has been limited reliable or useable data available to assess its status and investigate longterm population trends with confidence or certainty (Shaughnessy et al. 2011, Goldsworthy et al. 2015).

Despite the fact that the ASL has been listed as Endangered under the IUCN Red List since 2008 (Goldsworthy \& Gales 2008, Goldsworthy 2015), the species has been listed as 'vulnerable' under Australia's Commonwealth and State environment legislations (Environment Protection and Biodiversity Conservation Act of 1999 [EPBC Act]; SA National Parks and Wildlife Act of 1972; WA Biodiversity Conservation Act of 2016), even though a common assessment method using the IUCN criteria and thresholds has been applied in these jurisdictions. Different interpretations on past (limited) data and the marked variability in breeding site status and trends in abundance across its range have contributed to differences in the assessment of the species' conservation status (Woinarski et al. 2014). ASLs were recently (23 December 2020) uplisted to 'endangered' under the EPBC Act (Threatened Species Scientific Committee 2020). Consistency in the assessment of ASLs under the IUCN Red List and the Australian EPBC Act will reduce confusion among stakeholders about the status of this species. This consistency, plus an improved ability to detect changes in abundance, will underpin 
the development of a more cohesive and targeted policy and management framework for the recovery of the ASL.

With these issues in mind, the overarching goal of our study was to undertake a comprehensive species-wide assessment of the status of the ASL. Specifically, our aims were to (1) compile all historic ASL pup abundance time-series data; (2) evaluate and extract useable data; (3) assess the status and trends in abundance across breeding sites, subregions and metapopulations; and (4) identify and prioritise key data gaps and important factors to improve future population monitoring.

\section{METHODS}

\subsection{Source data}

The number of pups produced in a breeding season is a commonly used index of abundance for pinniped populations because pups form the only ageclass that is easily identifiable (black/brown lanugo), and most pups are ashore at the end of the breeding season and available for counting prior to moulting and dispersing. Although the relationship between pup production and the total population size is variable, depending on the status of the population (increasing, decreasing, stable), comparing pup counts can be a reliable indicator of population growth (Berkson \& DeMaster 1985).

A total of 1776 individual site surveys for all known ASL breeding sites in SA and WA between 1970 and 2019 were collated. Pup abundance counts have been obtained from ground, aerial, boat, cliff-top and, more recently, drone surveys. Four main methods were used: (1) standard ground counts of live and dead (or cumulative dead) pups; (2) adjusted ground counts where a known number of marked (or tagged) pups can be added to the maximum count of live and dead (or cumulative dead) unmarked pups; (3) markrecapture using the Petersen estimate; and (4) cumulative pup production based on either twice-weekly surveys of cumulative births (Seal Bay population), or from estimates of net pup production between successive mark-recapture surveys (Goldsworthy et al. 2015).

As the standard ground count is the default/basic survey method, these data form the basis to all time series analysis in this assessment. The only exception is for the Bunda Cliffs breeding sites, where cliff-top counts were used, as none of the sites are accessible on foot. Where multiple surveys have been conducted within a breeding season, individual surveys have included the cumulative number of dead pups. Dead pups are typically marked within surveys to avoid double counting. Most surveys include details on the number of live pups present in different pelage categories. This information is critical for estimating survey timing relative to the stage of the breeding season, as the pelage categories provide a proxy for pup age: black mateguarded (pups whose mothers are mate-guarded by an adult male are aged 0-10 d), black (post-mateguarded pups, 1-4 wk), brown (pups approximately 4-16 wk), moulting (pups 16-20 wk) and moulted (pups $>20$ wk).

\subsection{Evaluation and identification of comparable surveys}

The duration of ASL breeding seasons varies relative to the pup production of a given breeding site. For breeding sites that produce $<150$ pups, the breeding season typically lasts $4-5 \mathrm{mo}$, and a single survey is adequate if conducted at the right time, as the maximum count of pups occurs at the end of the breeding season. The end of the breeding season is indicated by an absence (or low numbers) of mateguarded or black pups and the presence of some moulting pups. Fully moulted pups are rarely recorded at the end of the breeding season for breeding sites that produce $<150$ pups.

For breeding sites producing $>150$ pups (Seal Bay, The Pages, Dangerous Reef), the breeding season may extend between 6 and 9+ mo in duration, and it is usual for fully moulted pups to be present alongside newborn (black) pups. For these sites, the peak in pup numbers usually occurs well before the end of the breeding season, due to a decrease in detectability as moulted pups become more aquatic (i.e. foraging at sea, dispersing). Multiple within-season surveys are often undertaken at larger breeding sites to increase the likelihood of counting at the 'peak' in pup numbers.

To evaluate if surveys provided data collected at a similar stage of breeding (i.e. admissible data) and hence suitable for time-series analysis, the distribution of pups in the 3 main pelage categories (black, brown, moulted) relative to the size of the breeding population was assessed. Additional observations (notes) made by observers on the timing of the survey relative to the stage of the breeding season were also considered. Two or more surveys of a given site in different breeding seasons were evaluated to be 
'comparable' if they were made at a similar time within each breeding season. A challenge with assessing the data of many early surveys is that categories of pups based on pelage were either not recorded ('unclassed'), or recorded inconsistently (e.g. brown pups in early moult were sometimes classed as moulted pups), or were recorded differently from recent surveys. For example, 'black mateguarded' and 'black' pups have only been regularly recorded in SA surveys since $\sim 2007$; prior to this, they were recorded as 'brown' pups.

Surveys were excluded from time-series analyses, if they were assessed to be: 'Early' (undertaken prior to, or early in the breeding season); 'Late' (undertaken well after the breeding season had ended); 'Unknown' (timing relative to the breeding season could not be evaluated); 'Incomplete' (evidence of inconsistent survey effort, i.e. parts of islands not surveyed where breeding may have taken place); or 'Incursions' (evidence that the timing of breeding of neighbouring breeding sites occurred earlier or was similar to the breeding site being surveyed; pup counts could be confounded [inflated] if there was significant movement of pups between sites, e.g. tagged Dangerous Reef pups sighted at Lewis, English and Albatross Islands; Nicolas Baudin Island pups sighted at Jones Island; Shaughnessy et al. 2005, Goldsworthy et al. 2008, 2009b, 2014).

\subsection{Time-series analysis}

ASL breeding sites with a time-series of pup abundance consisting of 3 or more comparable breeding seasons were used for these analyses. All sites with admissible data sets were analysed separately, except for those in the Bunda Cliffs, where site-by-site analysis of trends is challenging due to regular cliff collapses that have resulted in the loss of breeding habitat and sites over time. It is not clear what happens there when a breeding site is lost or becomes unsuitable, but presumably, some animals move to adjacent suitable habitat or to nearby established breeding sites. For these reasons, within-season surveys of pup abundance for the Bunda Cliffs breeding sites were pooled for the time-series analysis. For the pup abundance estimation, drone surveys in 2017 were used for the Bunda Cliffs region.

The change in pup numbers over time (with parts of years expressed as decimals) was estimated using regression analysis, which applied a linear regression of the natural logarithm of pup numbers against year. All analyses were undertaken in the software R, version 3.5.1 (R Core Team 2017), using the package 'lme4' (Bates et al. 2015).

The exponential rate of change $(r)$ (slope of the regression line) was expressed as a percentage rate of growth $(\lambda)$ as:

$$
\lambda=100\left(\mathrm{e}^{r}-1\right)
$$

An exponential decline was assessed to be the most appropriate for ASL, based on the pattern of decline observed in some subpopulations (Goldsworthy et al. 2019, 2020). In addition, as fisheries bycatch is a key threat to the species, and mortality rates (in demersal gillnet fisheries) vary as a function of ASL density, populations exposed to consistent fishing effort would be expected to show a constant proportional rate of decline (i.e. decline exponentially, Goldsworthy et al. 2010).

\subsection{Assessment against IUCN Red List criteria}

Assessment of the status of ASL against IUCN Red List criterion A2(a) (reduction in population size over 3 generations $\geq 80 \%$ : Critically Endangered, $\geq 50 \%$ : Endangered and $\geq 30 \%$ : Vulnerable) followed IUCN Red List guidelines (IUCN Standards and Petitions Committee 2019). A generation time of 14.1 yr was estimated for the species using the IUCN generation length calculator tool (https://www.iucnredlist.org/ resources/generation-length-calculator) and data on observed ASL fecundity and survival from the Seal Bay ASL subpopulation, which is the only site for the species where detailed demographic data are available (Goldsworthy et al. 2020). For each breeding site, the intercept and coefficient terms from the regression were used to estimate past (1977) and present (2019) pup abundances, and from these, the overall change in pup abundance over 3 generations (42.3 yr) was estimated.

A sensitivity analysis was undertaken following IUCN Guidelines for dealing with uncertainty (IUCN Standards and Petitions Committee 2019). The probability distributions for the back and forward projected estimates of pup abundances for each subpopulation with time-series data were estimated using the mean value and the $95 \%$ CI (converted to a standard deviation) for the earliest and most recent surveys from regression analyses. Using the Monte Carlo simulation method, these probability distributions were used to provide a measure of the uncertainty around past and present abundance estimates, from which a pair of past and present breeding site pup abundance estimates were randomly selected, a 
3-generation change was calculated, and the procedure was repeated 1000 times. By summing all of the past and present breeding site abundances for each simulation, the probability distribution for the reduction in ASL population size could be estimated, and from this the percentage of iterations where pup abundances had declined by more than $30 \%$ (Vulnerable) and 50\% (Endangered) was determined.

Because the management of ASL falls under both state and national environmental legislation, results are primarily presented at both the whole of species (national) and state level to facilitate management, rather than at the level of region or metapopulation.

\section{RESULTS}

\subsection{Breeding sites and pup abundance}

Breeding sites for the species are distributed from The Pages Islands just off Kangaroo Island, SA, in the east, west across the southern coast of Australia and north along the west coast of WA to Easter Island in the Abrolhos Islands. The breeding range can be subdivided into 3 main and discrete regions or metapopulations: South Australia (SA), south coast WA (SC-WA) and west coast WA (WC-WA) (Fig. 1). The distance between the nearest breeding sites in the SA and SC-WA and the SC-WA and WC-WA metapopulations is $>500$ and $>700 \mathrm{~km}$, respectively (Fig. 1). There is a single breeding site at Twilight
Cove (WA), between the SA and SC-WA metapopulations, $>200$ and $>300 \mathrm{~km}$ from the nearest breeding sites in the SC-WA and SA metapopulations, respectively; it can be considered as a fourth, minor metapopulation (Fig. 1). Within these metapopulations, 12 regional groups of breeding sites have been identified. These are based on the 11 subregions identified by Goldsworthy et al. (2007) with their WC-WA subregion divided into 2 subregions, Jurien Bay and Abrolhos Islands. The 12 subregions identified here are: Kangaroo Island, Spencer Gulf, SW Eyre, Chain of Bays, Nuyts Archipelago, Nuyts Reef, Bunda Cliffs, Twilight Cove, Recherche Archipelago, Bremer Bay, Jurien Bay and Abrolhos Islands (Fig. 1).

A total of 80 extant ASL breeding sites (subpopulations) were identified, with $48(60 \%)$ in $\mathrm{SA}$, and 32 $(40 \%)$ in WA (Table 1$)$. There is uncertainty about the breeding status of some sites where only single records of black or brown pups were available (Middle Doubtful, Rat, Morley and Campbell Islands, all in WA), and where only large brown or moulted pups were seen that may have originated from other nearby breeding sites (North Islet, SA; Middle Doubtful Island, SC-WA, and a number of the Abrolhos islands: Square, Lagoon, Keru, Helms, Sandy, West Wallabi and Wooded Island, WC-WA).

The total species-wide pup abundance is 2739 , of which $82 \%$ (2246) occur in SA and $18 \%$ (493) in WA (Table 1). This is based on the most recent and/or best available surveys for each site which extend from 1989 to 2019, but mostly between 2014 and

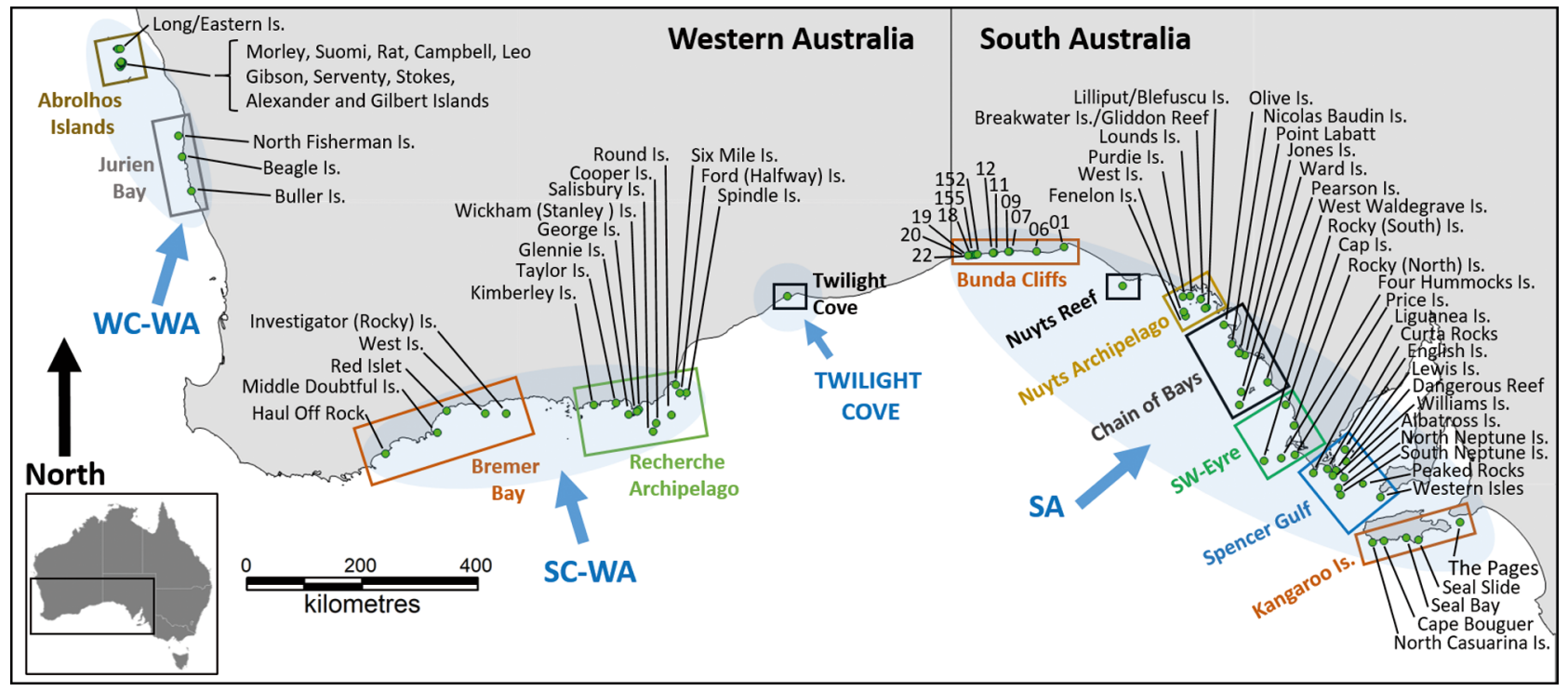

Fig. 1. Australian sea lion breeding sites within 12 regions (Kangaroo Island, Spencer Gulf, SW Eyre, Chain of Bays, Nuyts Archipelago, Nuyts Reef, Bunda Cliffs, Twilight Cove, Recherche Archipelago, Bremer Bay, Jurien Bay, Abrolhos Islands) and 3 major (SA: South Australia; SC-WA: south coast Western Australia; WC-WA: west coast WA) and 1 minor (Twilight Cove) metapopulations (identified by blue shading) 


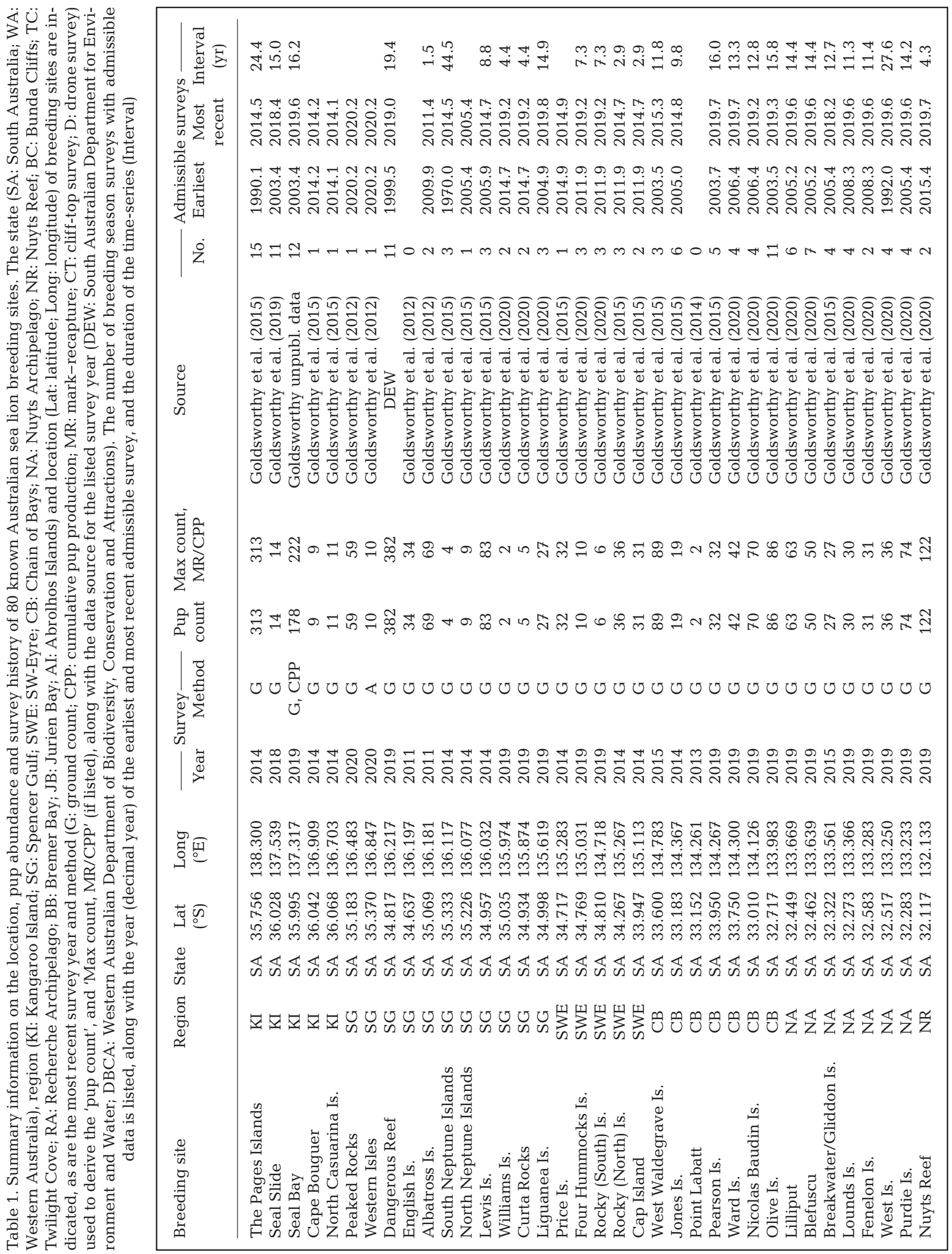




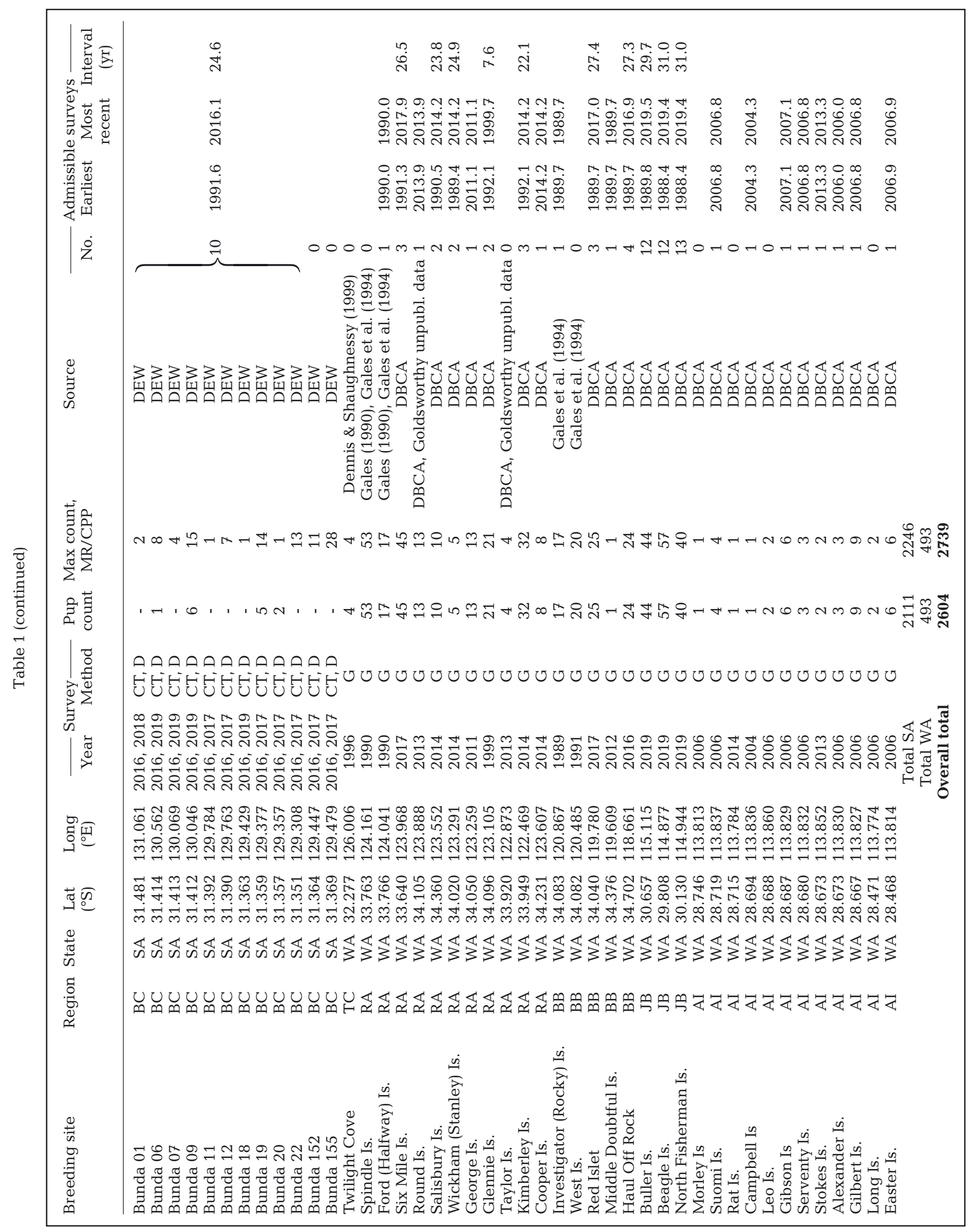




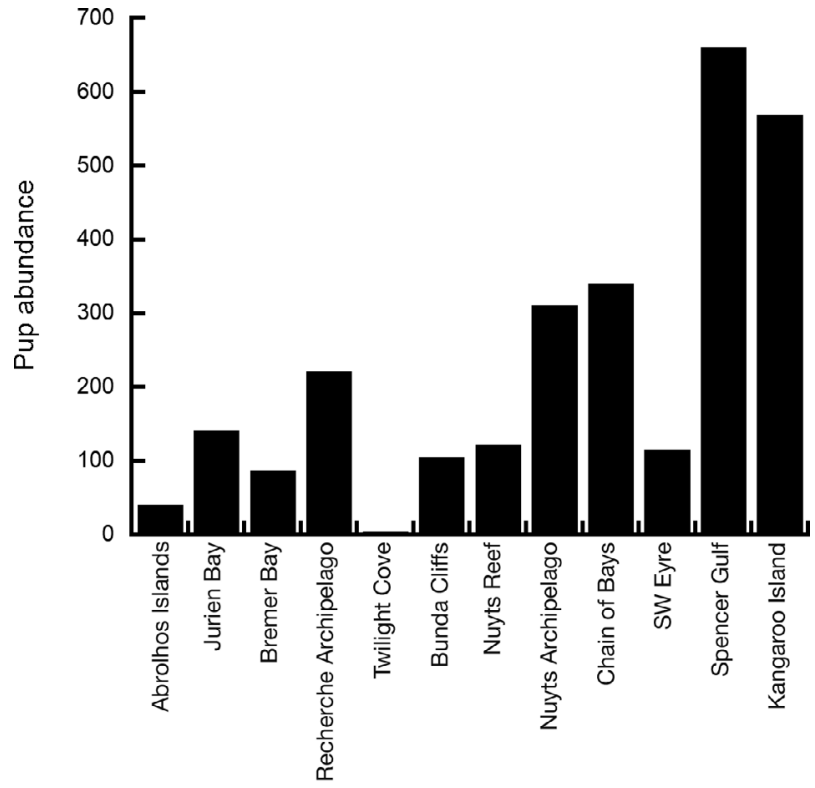

Fig. 2. Comparison of the distribution of regional totals of Australian sea lion pups, highlighting the general increasing cline in pup abundance by region from the western to the eastern part of the species' range

2019. There is a general cline in regional pup abundances, increasing from west to east across the species' range, largely reflecting the greater pup abundance in SA, but also larger breeding sites (Fig. 2). Only 4 sites produce more than 100 pups in a breeding season, and all are in SA (The Pages Islands, Seal Bay, Dangerous Reef, Nuyts Reef). These sites make up $38 \%$ of total pup abundance but just $5 \%$ of breeding sites. Most (81\%) breeding sites produce fewer than 50 pups in a breeding season, and $56 \%$ produce fewer than 20 (Table 1). The species-wide median pup abundance per breeding site is just 14 (27.0 in $\mathrm{SA}, 8.5$ in WA).

Baseline data, defined as having admissible data from at least 1 survey, were available for $70(88 \%)$ of the 80 breeding sites across the species' range (96\% of SA and $75 \%$ of WA sites) (Table 2). Contemporary

Table 2. Number of Australian sea lion breeding sites by state (SA: South Australia; WA: Western Australia), and the number (\%) with baseline data (at least 1 survey with admissible data), with contemporary estimates (at least 1 admissible survey obtained in the last decade), and 3 or more comparable (admissible) surveys

\begin{tabular}{|lcccc|}
\hline State & $\begin{array}{c}\text { Breeding } \\
\text { sites }\end{array}$ & $\begin{array}{c}\text { Baseline } \\
\text { data (\%) }\end{array}$ & $\begin{array}{c}\text { Contemporary } \\
\text { estimate (\%) }\end{array}$ & $\begin{array}{c}\geq 3 \text { comparable } \\
\text { surveys (\%) }\end{array}$ \\
\hline SA & 48 & $46(96)$ & $46(96)$ & $23(48)$ \\
WA & 32 & $24(75)$ & $14(44)$ & $7(22)$ \\
Total & 80 & $70(88)$ & $60(75)$ & $30(38)$ \\
\hline
\end{tabular}

estimates, with at least 1 admissible survey obtained in the last decade, were available for $60(75 \%)$ of the 80 breeding sites ( $96 \%$ of SA and $44 \%$ of WA sites) (Table 2).

\subsection{Trends in abundance}

Of the 1776 individual site-surveys evaluated, just $228(13 \%)$ from 60 breeding sites were judged to provide admissible data. Of these, 189 surveys from 30 breeding sites (38\% of total breeding sites) had 3 or more comparable breeding season surveys suitable for trend analysis (Table 2, Fig. 3). Of these 30 breeding sites, $77 \%$ were in SA and $23 \%$ were in $\mathrm{WA}_{\text {; }}$ furthermore, they accounted for $74 \%$ of the species-wide pup abundance $(79 \%$ of SA, and $54 \%$ of WA pup abundance). The duration between the earliest and most recent survey ranged between 1.5 and $44.5 \mathrm{yr}$ $($ mean $=16.4 \mathrm{yr})$ for all breeding sites (Table 1$)$, and between 2.9 and $44.5 \mathrm{yr}$ (mean = $18.5 \mathrm{yr}$ ) for breeding sites with 3 or more comparable surveys (Table 3 ).

Results of regression analyses undertaken on the 30 breeding sites with 3 or more comparable pup abundance surveys are detailed in Table 3 and Fig. 3 . The average growth rate among the 30 breeding sites was $-2.0 \% \mathrm{yr}^{-1}$ (range -9.9 to $1.7 \% \mathrm{yr}^{-1}, \mathrm{SD}=$ $3.0 \%$ ) and varied considerably among breeding sites (Fig. 4). For SA, the average growth rate was $-2.6 \%$ $\mathrm{yr}^{-1}(\mathrm{SD}=3.2 \% ; \mathrm{n}=23$ sites$)$ and for $\mathrm{WA}$, it was $-0.3 \% \mathrm{yr}^{-1}(\mathrm{SD}=0.6 \% ; \mathrm{n}=7$ sites) (Table 3). Overall, the median growth rate was $-1.2 \% \mathrm{yr}^{-1}$.

There was no clear geographic pattern in the growth rates of breeding sites among or within regions (Tables $3 \& 4$ ). The greatest rates of decline were in the SW Eyre $\left(-8.7 \% \mathrm{yr}^{-1}\right)$ and Bunda Cliffs $\left(-5.9 \% \mathrm{yr}^{-1}\right)$ regions, followed by the Nuyts Archipelago $\left(-1.9 \% \mathrm{yr}^{-1}\right)$, Chain of Bays $\left(-1.6 \% \mathrm{yr}^{-1}\right)$ and Spencer Gulf $\left(-1.5 \% \mathrm{yr}^{-1}\right)$ (Table 4$)$. The lowest declines were in the Recherche Archipelago and Bremer Bay regions (both $-0.6 \% \mathrm{yr}^{-1}$ ), and Kangaroo Island $\left(-0.1 \% \mathrm{yr}^{-1}\right)$ (Table 4$)$. The only region recording stable/positive growth was the Jurien Bay region (Table 4). Changes in population growth rates could not be determined for Nuyts Reef, Twilight Cove or the Abrolhos Islands regions.

\subsection{Population reduction}

Regression analyses undertaken on the 30 breeding sites with 3 or more comparable surveys were used to estimate the reduction between past and 


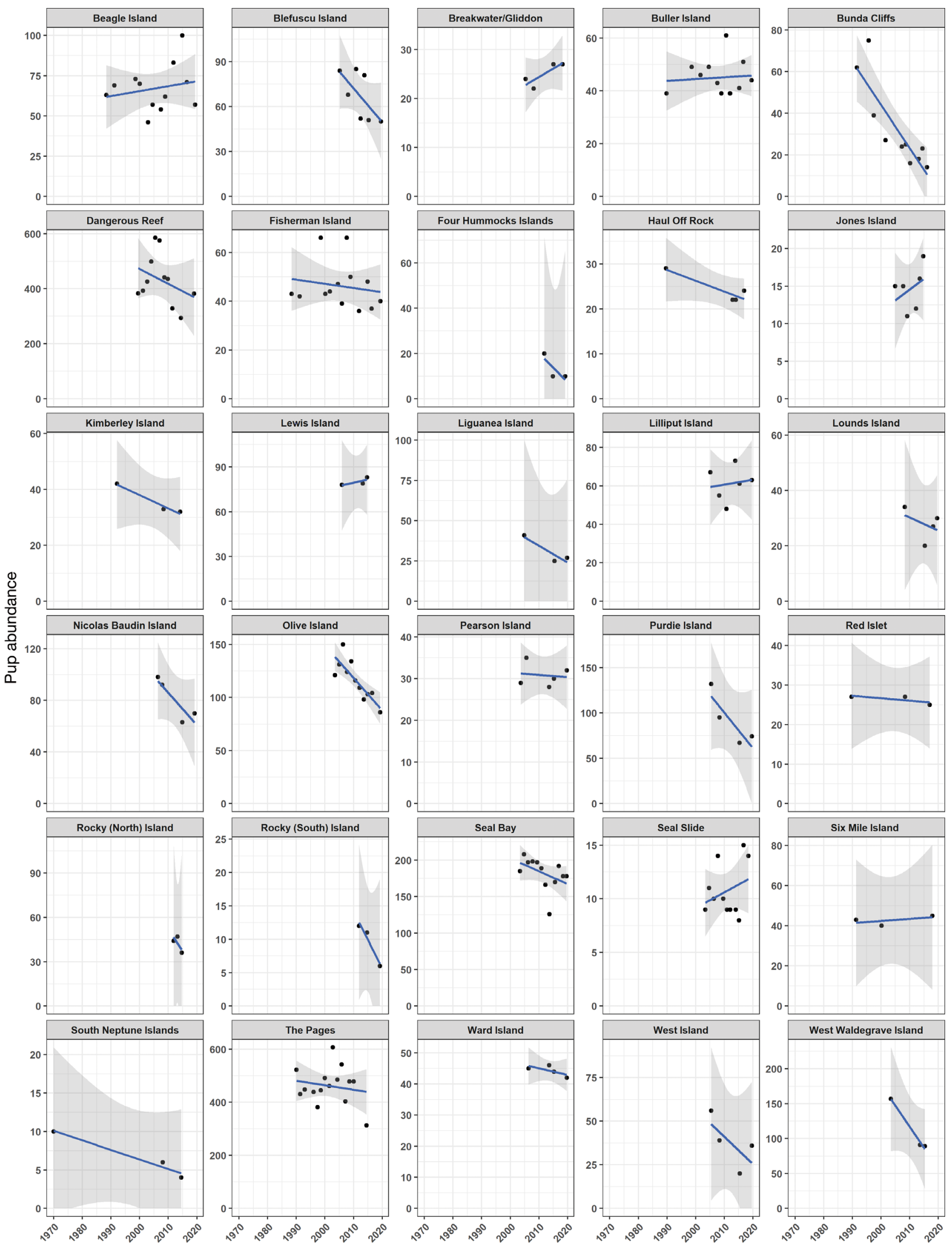

Fig. 3. Trends in pup abundance for 30 Australian sea lion subpopulations with 3 or more comparable surveys. The plots show changes in pup abundance over time for each breeding site, to which an exponential regression model with $\pm 95 \%$ confidence 
Table 3. Summary results of trend analyses for the 30 Australian sea lion breeding sites with 3 or more comparable surveys across 3 regions (SA: South Australia; SC-WA: south coast Western Australia; WC-WA: west coast WA). The year (decimal year) of the earliest and most recent comparable survey at each breeding site is provided, along with the time-series duration and number of surveys. For each site, the estimated change in past and present pup abundances over a 3-generation period (42.3 yr) between 1977.2 (1977) and 2019.5 (2019) is provided, along with intrinsic rate of change (r), and estimated 3-generation change $(\%)$. The mean $r$, summed pup abundance $(1977,2019)$ and 3-generation change $(\%)$ in pup abundances are also provided at the bottom of the table for SA, WA and the overall population. The time-series data and sources are provided in

Table S1 in the Supplement at www.int-res.com/articles/suppl/n044p421_supp.pdf

\begin{tabular}{|c|c|c|c|c|c|c|c|c|c|}
\hline Breeding site & Region & $\begin{array}{l}\text { Earliest } \\
\text { survey }\end{array}$ & $\begin{array}{c}\text { Most recent } \\
\text { survey }\end{array}$ & $\begin{array}{l}\text { Time series } \\
\text { duration }(\mathrm{yr})\end{array}$ & $\begin{array}{c}\text { Number of } \\
\text { surveys }\end{array}$ & $r$ & $\begin{array}{l}\text { Pups } \\
1977\end{array}$ & $\begin{array}{l}\text { Pups } \\
2019\end{array}$ & $\begin{array}{c}\text { Estimated 3-gen } \\
\text { change }(\%)\end{array}$ \\
\hline The Pages & SA & 1990.1 & 2014.5 & 24.4 & 15 & -0.005 & 514 & 418 & -18.6 \\
\hline Seal Slide & SA & 2003.4 & 2018.4 & 15.0 & 11 & 0.011 & 7 & 12 & 58.9 \\
\hline Seal Bay & SA & 2003.4 & 2019.6 & 16.2 & 12 & -0.010 & 253 & 167 & -33.9 \\
\hline South Neptune Islands & SA & 1970.0 & 2014.5 & 44.5 & 3 & -0.018 & 9 & 4 & -53.5 \\
\hline Dangerous Reef & SA & 1999.5 & 2019.0 & 19.4 & 11 & -0.014 & 639 & 359 & -43.8 \\
\hline Lewis Is. & SA & 2005.9 & 2014.7 & 8.8 & 3 & 0.005 & 67 & 84 & 25.5 \\
\hline Liguanea Is. & SA & 2004.9 & 2019.8 & 14.9 & 3 & -0.032 & 95 & 25 & -73.6 \\
\hline Rocky (South) Is. & SA & 2011.9 & 2019.2 & 7.3 & 3 & -0.099 & 396 & 6 & -98.5 \\
\hline Four Hummocks Islands & SA & 2011.9 & 2019.2 & 7.3 & 3 & -0.088 & 366 & 9 & -97.6 \\
\hline Rocky (North) Is. & SA & 2011.9 & 2014.7 & 2.9 & 3 & -0.074 & 615 & 26 & -95.7 \\
\hline Jones Is. & SA & 2005.0 & 2014.8 & 9.8 & 6 & 0.017 & 8 & 17 & 109.3 \\
\hline West Waldegrave Is. & SA & 2003.5 & 2015.3 & 11.8 & 3 & -0.050 & 584 & 70 & -88.0 \\
\hline Pearson Is. & SA & 2003.7 & 2019.7 & 16.0 & 5 & -0.001 & 32 & 30 & -6.1 \\
\hline Ward Is. & SA & 2006.4 & 2019.7 & 13.3 & 4 & -0.005 & 53 & 43 & -18.7 \\
\hline Nicolas Baudin Is. & SA & 2006.4 & 2019.2 & 12.8 & 4 & -0.031 & 234 & 63 & -73.1 \\
\hline Olive Is. & SA & 2003.5 & 2019.3 & 15.8 & 11 & -0.027 & 286 & 90 & -68.4 \\
\hline Lilliput Is. & SA & 2005.2 & 2019.6 & 14.4 & 6 & 0.005 & 52 & 63 & 21.5 \\
\hline Blefuscu Is. & SA & 2005.2 & 2019.6 & 14.4 & 7 & -0.035 & 225 & 51 & -77.5 \\
\hline Breakwater/Gliddon Is. & SA & 2005.4 & 2018.2 & 12.7 & 4 & 0.014 & 15 & 28 & 79.8 \\
\hline Lounds Is. & SA & 2008.3 & 2019.6 & 11.3 & 4 & -0.015 & 49 & 26 & -47.7 \\
\hline West Is. & SA & 1992.0 & 2019.6 & 27.6 & 4 & -0.041 & 149 & 26 & -82.4 \\
\hline Purdie Is. & SA & 2005.4 & 2019.6 & 14.2 & 4 & -0.041 & 375 & 66 & -82.5 \\
\hline Bunda Cliffs & SA & 1991.6 & 2016.1 & 24.6 & 10 & -0.059 & 150 & 12 & -91.9 \\
\hline Six Mile Is. & SC-WA & 1991.3 & 2017.9 & 26.5 & 3 & 0.002 & 40 & 44 & 10.7 \\
\hline Kimberley Is. & SC-WA & 1992.1 & 2014.2 & 22.1 & 3 & -0.013 & 51 & 29 & -41.9 \\
\hline Red Islet & SC-WA & 1989.7 & 2017.0 & 27.4 & 3 & -0.002 & 28 & 25 & -9.5 \\
\hline Haul Off Rock & SC-WA & 1989.7 & 2016.9 & 27.3 & 4 & -0.009 & 32 & 22 & -32.6 \\
\hline Buller Is. & WC-WA & 1989.8 & 2019.5 & 29.7 & 12 & 0.001 & 43 & 45 & 6.1 \\
\hline Beagle Is. & WC-WA & 1988.4 & 2019.4 & 31.0 & 12 & 0.004 & 59 & 69 & 16.3 \\
\hline North Fisherman Is. & WC-WA & 1988.4 & 2019.4 & 31.0 & 13 & -0.004 & 51 & 43 & -15.1 \\
\hline South Australia & & & & & & -0.026 & 5174 & 1694 & -67.2 \\
\hline Western Australia & & & & & & -0.003 & 304 & 278 & -8.4 \\
\hline Overall & & & & & & -0.020 & 5477 & 1973 & -64.0 \\
\hline
\end{tabular}

present pup abundances over a period of 3 generations (42.3 yr) between 1977.2 (1977) and 2019.5 (2019) (Table 3). Overall, pup abundance estimates were 5477 in 1977 and 1973 in 2019, giving an estimated decline over 3 generations of $64.0 \%$ (Table 3 ).

The probability distribution of the reduction in the ASL population over 3 generations based on Monte Carlo simulations indicates that the probability that the pup abundances have declined by at least 30\% over a 3-generation period was $100 \%$ (1000 of 1000 simulations), and the probability that they have declined by at least $50 \%$ over a 3-generation period was $>98 \%$ (>980 of 1000 simulations) (Fig. 5). The median decline in pup abundance over 3 generations was $61 \%$.

\section{DISCUSSION}

\subsection{Species-wide assessment}

This study provides the first quantitative estimate of the trends in abundance of ASL populations across their range, although trends could not be determined for some subregions. We found that the ASL population is much smaller than previously estimated, and is declining. This reduction in population size (based on pup abundance) exceeds $50 \%$ over a period of 3 generations (42.3 yr), and clearly meets the 'Endangered' criteria (decline $\geq 50 \%$ and $\leq 80 \%$ ) under IUCN Criterion A2b (namely, A2: 'Population reduction observed, estimated, inferred, or suspected in the 


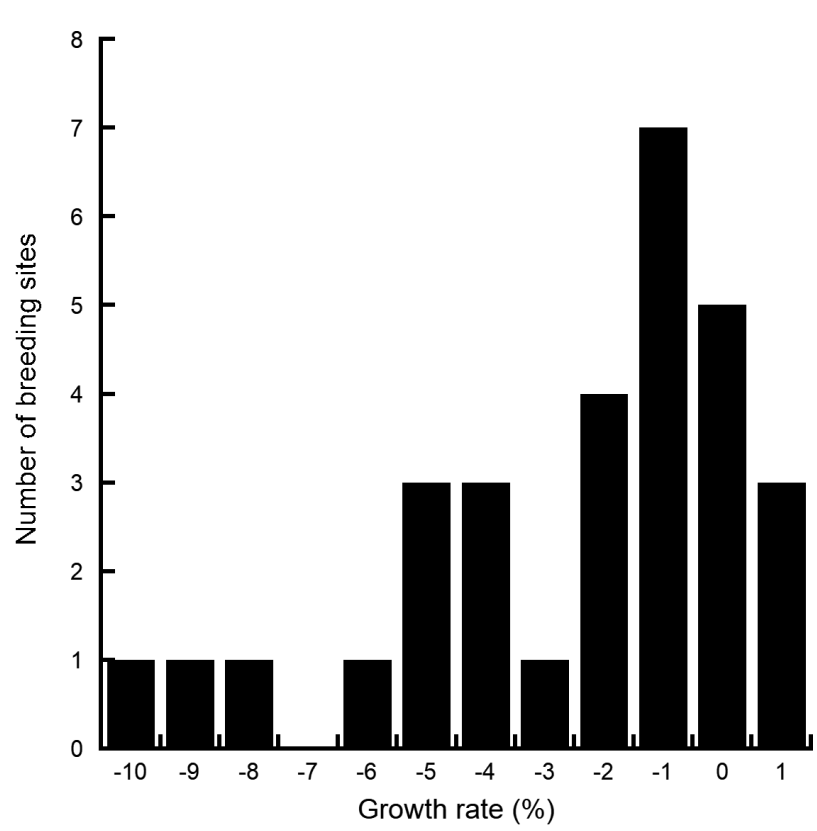

Fig. 4. Estimated growth rates of 30 Australian sea lion subpopulations, based on 3 or more comparable surveys of pup abundance

Table 4. Summary by region of the number of Australian sea lion breeding sites, the number of sites with admissible timeseries data ( 3 or more comparable surveys) and the average intrinsic rate of growth $(r)$. (-) no average for these regions

\begin{tabular}{|lccc|}
\hline Region & $\begin{array}{c}\text { No. } \\
\text { sites }\end{array}$ & $\begin{array}{c}\text { With } \\
\text { admissible } \\
\text { time series }\end{array}$ & $\begin{array}{c}\text { Average } \\
r\end{array}$ \\
\hline Kangaroo Island & 5 & 3 & -0.001 \\
Spencer Gulf & 11 & 4 & -0.015 \\
SW Eyre & 5 & 3 & -0.087 \\
Chain of Bays & 7 & 6 & -0.016 \\
Nuyts Archipelago & 7 & 6 & -0.019 \\
Nuyts Reef & 1 & 0 & - \\
Bunda Cliffs & 12 & 1 & -0.059 \\
Twilight Cove & 1 & 0 & - \\
Recherche Archipelago & 11 & 2 & -0.006 \\
Bremer Bay & 5 & 2 & -0.006 \\
Jurien Bay & 3 & 3 & 0.000 \\
Abrolhos Islands & 12 & 0 & - \\
& \multicolumn{3}{l}{} \\
aFor the Bunda Cliffs region, all breeding site data were \\
pooled within surveys \\
\hline
\end{tabular}

past where the causes of reduction may not have ceased OR may not be understood OR may not be reversible' and b: 'an index of abundance appropriate to the taxon') (IUCN Standards and Petitions Committee 2019, p. 16). Results from our study are consistent with the current IUCN Red List assessment for the species (Goldsworthy 2015). Three important considerations provide confidence that the

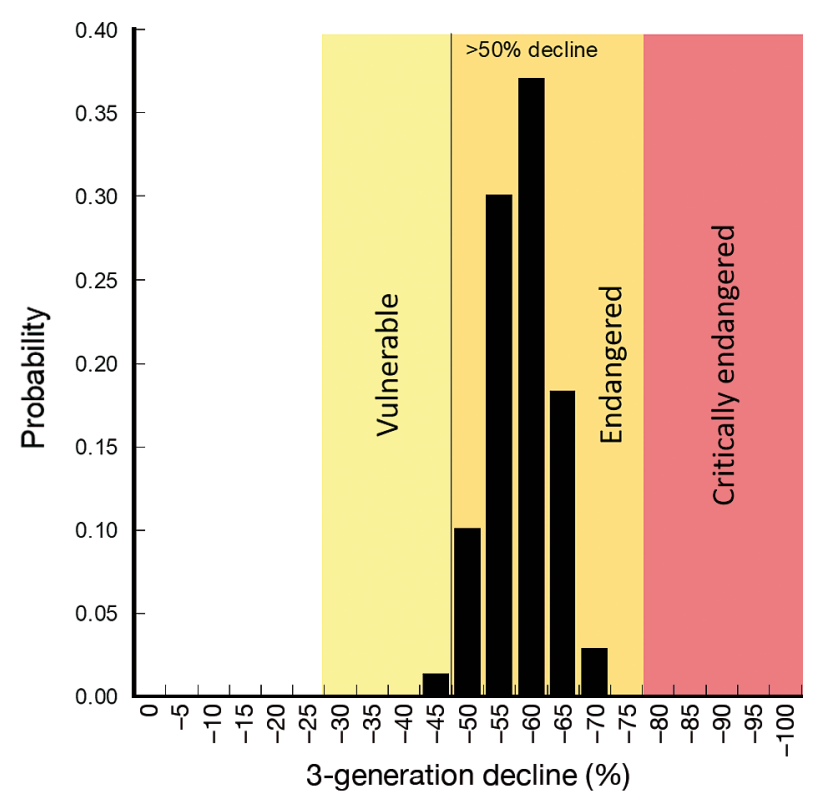

Fig. 5. Probability distribution of Monte Carlo simulations of the decline over 3 generations in 30 Australian sea lion breeding sites, where at least 3 comparable pup abundance surveys have been undertaken. The vertical line indicates the threshold for IUCN 'Endangered' status corresponding to a $>50 \%$ decline

species-wide assessment in trends in abundance is both representative and robust: the 30 sites where trends in abundance could be estimated account for over $75 \%$ of the species-wide pup abundance; they span most of the geographic range of the species; and our assessment of population reduction is relatively insensitive to the error distributions around past and present breeding site pup abundances (over $98 \%$ of Monte Carlo simulations produced a decline of $>50 \%$ over a 3 -generation period).

The average rates of declines in pup abundances were greater for SA $\left(-2.6 \% \mathrm{yr}^{-1}\right)$ compared to WA $\left(-0.3 \% \mathrm{yr}^{-1}\right)$ breeding sites. However, this apparent difference may be an artefact of the low survey effort across large parts of the WA ASL distribution. Most $(\sim 75 \%)$ of the WA time-series data come from just 3 sites within a state marine reserve in the Jurien Bay region (which accounts for $29 \%$ of the WA ASL pup abundance) that have been frequently surveyed over the last 30 yr. It is unclear how representative the Jurien Bay breeding sites are of ASL trends elsewhere in WA. Time-series data for the remaining WA regions (Abrolhos, Bremer Bay, Recherche Archipelago, Twilight Cove) that account for $71 \%$ of the WA ASL pup abundance are very limited, with just 13 admissible surveys across 4 of the remaining 29 breeding sites. 
Our results suggest that total pup abundance for the species (integrated across 80 known breeding sites) is at least $25 \%$ lower than that derived from an assessment based mostly on surveys conducted some 11 to 15 yr earlier (between 2004 and 2008) of 3622 pups (Shaughnessy et al. 2011). However, our study also included pup numbers from 6 recently discovered breeding sites (SA: Western Isles, Williams Island, Curta Rocks, Rocky [South] and Cap Islands; WA: George Island; their combined pup abundance was 67), and from 3 sites where earlier surveys appear to have been conducted either too early or outside the breeding season (Nuyts Reef, North Casuarina and Rocky [North] Islands, which underestimated pup abundance by at least 138 pups). These 2 factors suggest that earlier surveys may have underestimated pup number by at least 205. Accounting for these factors suggests an even greater decline of around $30 \%$ over the last $15 \mathrm{yr}$.

Shaughnessy et al. (2011) estimated the total size of the ASL population to be 14780 , based on multiplying pup numbers by 4.08 to estimate total population size. That multiplier was developed by Goldsworthy \& Page (2007) and was based on a generic otariid life-table developed by Goldsworthy et al. (2003), adjusted for a $1.5 \mathrm{yr}$ breeding interval and female longevity of $25 \mathrm{yr}$. A more recent ASL life-table that utilised survival estimates from the Seal Bay population, adjusted to achieve a stable population growth, derived a multiplier of pup numbers to total population size of 3.83 (Goldsworthy et al. 2010). With this multiplier, the size of the ASL population based on surveys from 2004 to 2008 becomes 13872; and for the present study (surveys up to 2019) it is 10402 . These are likely to be over-estimates because the appropriate multiplier depends on the growth rates of the populations (Harwood \& Prime 1978), which are known to differ among breeding sites. In both instances, the ASL population was assumed to be stable, but the reduction in pup abundance between the 2 surveys indicates that a lower multiplier may be more appropriate, and that the total population may number $<10000$ individuals. However, how estimates of pup abundance relate to actual pup production and population size is poorly understood for the ASL.

Although our study identified a general increase in the size of regional ASL populations from west to east across the species' range, one of the more perplexing observations is the marked within-region variability in the size and trends in abundance of individual ASL breeding sites. Although the largest breeding sites (including the 4 that produce more than 100 pups) are in SA, breeding sites of varying size and trends (de- clining, stable or increasing) occur in close proximity to each other. For example, the Nuyts Archipelago region contains 7 breeding sites within a $25 \mathrm{~km}$ radius. Trend data are available for 6 of these sites, 3 of which have been declining by more than $3 \% \mathrm{yr}^{-1}$ (Purdie, West, Blefluscu Islands), 1 that is declining by $\sim 1.5 \% \mathrm{yr}^{-1}$ (Lounds Island) and 2 that are stable or increasing (Lilliput Island, Breakwater/Gliddon Reef).

Inasmuch as the strong cline in regional abundances points to the influence of larger-scale oceanographic processes driving a general increase in coastal marine productivity (and ASL population size) from west to east (van Ruth et al. 2010), the marked within-region heterogeneity in the size and trends in ASL breeding sites points to the importance of local-scale factors in shaping within-region differences in population dynamics. The latter is likely enhanced by marked intersite and inter-individual differences in foraging strategies, which have been identified from satellite telemetry studies (Goldsworthy et al. 2009c, Lowther \& Goldsworthy 2011a,b). As such, there is potential for marked inter-individual and inter-site variability in exposure to natural and anthropogenic risks.

\subsection{Historic and current impacts on populations}

Limited historic information is available on the size and range of ASL populations prior to European colonisation. As with fur seals, the species was subject to uncontrolled sealing following European settlement, but the numbers recorded to have been taken between 1800 and 1830 (4116) and in 18511852 (745) are small relative to the numbers of Australian fur seals Arctocephalus pusillus doriferus and long-nosed fur seals A. forsteri (350 000) (Ling 1999, Stuart 2018). Historic accounts indicate that the range of ASL once extended east to the southern Furneaux (Clarke, Passage and Battery Islands) and Kent Group in Bass Strait (Warneke 1982), but there is great uncertainty about the size and range of presealing populations, about the impact that sealing had on population size and on the extent of recovery that may have subsequently taken place. However, the reduction in population size, and declining trends in pup abundance reported in this study, suggest broad-scale depletion in recent decades. As such, the current distribution of abundance across the range of the species is likely to reflect both historical and contemporary impacts.

The ASL Recovery Plan identifies a range of impacts as potential factors contributing to the lack of recovery and decline of ASL populations (Depart- 
ment of Sustainability Environment Water Population and Communities 2013). These include deaths caused by bycatch in fisheries, interactions with aquaculture operations and entanglement in marine debris; habitat degradation and prey depletion; human disturbance to breeding sites (including tourism); deliberate killings; disease; pollution and oil spills; and climate change with potential inundation of breeding sites and changes to food webs and prey availability (Goldsworthy et al. 2009a). Data on the relative and cumulative importance of these factors is limited. Known impacts include fisheries bycatch (especially in demersal gillnets), entanglement in marine debris and disease (hookworm) (Page et al. 2004, Goldsworthy \& Page 2007, Goldsworthy et al. 2010, Hamer et al. 2013, Marcus et al. 2014, 2015). The relative impacts of these on the population sustainability has only been assessed for bycatch in the demersal gillnet fishery off SA. Between 2006 and 2009 , bycatch mortality was estimated to be unsustainable over much of the species' range, and was likely to have resulted in declines observed at some breeding sites (Goldsworthy et al. 2010). Between 2010 and 2012, the Australian Fisheries Management Authority introduced a range of management measures into the gillnet, hook and trap fishery off SA to mitigate bycatch of ASL, including spatial closures around all ASL breeding sites, electronic monitoring of fishing activity, bycatch trigger limits and the ability to use alternate fishing methods (hooks) (Australian Fisheries Management Authority 2015). Logbook data on ASL interactions reported since 2012 suggest that these measures have reduced ASL bycatch mortality in that fishery, but the extent to which they have reduced population declines is unknown. A separately managed demersal gillnet fishery occurs off WA and is also known to have interactions with ASL. Spatial closures have been recently introduced into that fishery (2018), but with no independent monitoring of fishing activity (and bycatch rates), the success of these closures in reducing ASL mortality is uncertain. The bycatch of ASL pups and juveniles in rock lobster pots has been largely mitigated through the introduction of potspikes in rock lobster fisheries off WA and SA (Campbell et al. 2008a, Goldsworthy et al. 2010, Mackay \& Goldsworthy 2017).

\subsection{Survey gaps and methodology}

This study has identified some key data gaps and deficiencies in knowledge of the status and trends in
ASL populations. As detailed above, key regions that are poorly represented include the Abrolhos Islands, Bremer Bay, Recherche Archipelago and Twilight Cove, all in WA. These regions have had low survey effort over recent decades based in part on their remoteness and lack of accessibility. As a consequence, when surveys are undertaken, there is a high likelihood they will occur outside the breeding season and not provide admissible data. Less than half of these sites $(45 \%)$ have had an admissible, contemporary survey within this last decade, and only $14 \%$ of them have 3 or more comparable surveys from which a trend in abundance can be estimated. The situation for SA populations is much better, but there are still a number of breeding sites with no baseline surveys, or for which an acceptable survey has only been achieved recently. More than half of the breeding sites still lack enough comparable surveys from which to assess trends. Committing to a more systematic survey approach is the only way to address these key gaps and improve confidence in the status and trends in abundance of ASL across their range.

Given the asynchronous breeding pattern of the species, a critical aspect of survey success (irrespective of the methodology used) is timing the surveys of individual sites appropriately with respect to their breeding season and their pup production. As noted in Section 2, the duration of an ASL breeding season in a particular breeding site varies with its pup production, and this affects how surveys are designed/ planned, particularly the number of surveys and their timing relative to the beginning and end of the pupping season. For most breeding sites (<150 pups), a single appropriately timed survey at the end of the breeding season is sufficient. As pup production and the duration of the breeding season increase, so does the likelihood that early-born pups will have moulted before the end of the breeding season, be more aquatic and less available to survey. For such sites, multiple surveys increase the likelihood of obtaining a count at 'peak' pup numbers and providing admissible data that can be used in trend analysis.

An added complication is that the interbreeding interval is not consistent within and between breeding sites. Although available data suggest that the breeding interval is generally between 17 and $18 \mathrm{mo}$, it can vary between breeding seasons and sites. At Seal Bay, the interbreeding interval ranges from 16 to 19.9 mo (Shaughnessy et al. 2006), but it has not been estimated so precisely for any other breeding site. This feature of the breeding biology has meant that planning the most appropriate time to survey a breeding site can be extremely challenging, espe- 
cially for sites that have not been surveyed for some years. As such, maintaining knowledge on the timing of breeding seasons for sites is critical to ensure the successful timing of future surveys. Beyond the timing of surveys, consistency in the survey approach is essential. In particular, accurate recognition of pup pelage categories during surveys is critical to determining survey timing relative to the stage of the breeding season, and in evaluating if the survey provides admissible data for trend analysis.

\subsection{Recommendations on future monitoring strategies for the species}

Population genetic studies on ASLs have indicated little or no interchange of females between breeding sites, even for those separated by short distances (Campbell et al. 2008b, Lowther et al. 2012). The important conservation implication from such extreme philopatry is that each breeding site is effectively a closed population. In light of this, conservation and management measures need to focus at the level of the breeding site (subpopulation). That half of the known ASL breeding sites produce fewer than 14 pups every $18 \mathrm{mo}$ with the likelihood that most sites are effectively closed subpopulations, heightens the conservation imperative to improve monitoring efforts. At the most basic level, identifying and managing threats to facilitate recovery of the species will be underpinned by an ability to detect changes in the status and trends of individual breeding sites/ subpopulations.

A future monitoring strategy is essential to meet the objectives of the Australian Sea Lion Recovery Plan (Department of Sustainability Environment Water Population and Communities 2013), and ensure that any recovery following management and threat mitigation (such as bycatch mortality in demersal gillnet fisheries) can be adequately assessed. Most historic monitoring has been ad hoc and opportunistic, resulting in many surveys being undertaken at the wrong time and providing inadmissible data. As a consequence, significant gaps in baseline data remain over much of the species' range, and limited time-series data are available to assess trends in abundance. Developing and committing to a more systematic monitoring strategy is essential to address these key gaps and enhance current monitoring of the species.

Recent survey efforts in SA using helicopters have improved access to breeding sites on islands compared to boat transport, thereby facilitating a marked increase in survey efficiency and capacity. The use of helicopters has enabled multiple sites to be surveyed within a day, quickly and efficiently, and has increased the capacity to monitor ASL regional breeding phenology (without necessarily having to land at each island). Given that many breeding sites are just tens of kilometres apart, it is feasible to survey all breeding sites within a region by helicopter over the course of 1-2 d. In past decades, ASL breeding sites were largely accessed by boat, limiting the number of sites that could be feasibly surveyed, with access often curtailed by unfavourable weather conditions. Such logistic constraints dictated a monitoring strategy focussed on a small number of 'key' (accessible) sites, which were hoped to be indicative of regional trends and abundance (Goldsworthy et al. 2009a,b, Pitcher 2018). Over the last decade, the monitoring strategy for ASLs in SA has changed to undertaking regionally comprehensive surveys, because helicopters make this feasible, efficient and cost-effective (Goldsworthy et al. 2015, 2020). This change has markedly improved the information on the status of ASLs at many breeding sites, resulted in the discovery of a number of new breeding sites, enabled regional trends in abundance to be assessed and facilitated a more comprehensive assessment of the conservation status of the species across its range.

ASLs typify many of the current issues facing global sea lion populations. Their dependence on shallow coastal seas exposes populations to increased interactions with human activities, which are the prevailing cause of the decline in most species (Kovacs et al. 2012). As high trophic-level marine megafauna, the status of sea lion populations reflects the health and integrity of their marine ecosystems, and they are harbingers of biodiversity loss and human impacts in our coastal seas (Boyd et al. 2006, Hazen et al. 2019). Improved monitoring of the species will increase the understanding of population dynamics and the targeting and assessment of critical conservation measures.

Acknowledgements. We thank the Australian Marine Mammal Centre (AMMC), the Department for Environment and Water (DEW) (SA) and the Department of Biodiversity, Conservation and Attractions (DBCA) (WA) for supporting the surveys of Australian sea lion breeding sites. Surveying of some breeding sites in SA was supported by in-kind funding received from the Great Australian Bight Research Program, a collaboration between BP, CSIRO, the South Australian Research and Development Institute (SARDI), The University of Adelaide and Flinders University. The work was conducted under an animal ethics permit from the SA Department of Primary Industry and Regions (PIRSA) Animal 
Ethics Committee (Approval No. 32-12) and the DEW, Scientific Research Permit (A24684). We thank Janice Goodwins, Sandy Carruthers and Lisien Loan (DEW) for facilitating recent surveys in SA, and Dr. Rebecca McIntosh (Phillip Island Nature Park), Clarence Kennedy, Melanie Stonnill, Tanya Rosewarne, Alana Binns, Martine Kinloch (DEW) and other DEW staff involved in Australian sea lion monitoring at Seal Bay and the Seal Slide on Kangaroo Island. For logistic assistance with island surveys, we thank Erin Gibson, Sam Hensche and Will Miles (Helifarm), Tony Jones (Protec Marine, Aqualinc Marine), Darren Guidera and Kangaroo Island Helicopters. For assistance with field work, we thank Jarrod Hodgson, Sol Kraitzer, Paul Rogers, Leonardo Mantilla, Alex Dobrovolskis and Ian Moody (SARDI), Kristian Peters, Andrew Sleep, Robbie Sleep, Yasmin Wolfe and Dyson Taverner (DEW), Emma Rowe, Lisa West, Matt Dasey, Vaughn Chapple, Melissa Evans, Miecha Bradshaw, Stephen Goodlich, Anthony Desmond, Jon Pridham, Sarah Comer and Stephen Butler (DBCA), Richard Campbell, David Holley, Kevin Crane, Paul Jennings and Peter Collins (formerly DBCA), Sylvia Osterrieder and Chandra SalgadoKent (formerly of Curtin University), Mathew Hourston (Department of Primary Industries and Regional Development) and Rory McAuley. We thank Professor Helene Marsh (Chair of Threatened Species Scientific Committee), Professor David Keith (University of New South Wales) and Dr. Ivan Lawler (Department of Agriculture, Water and the Environment) for analytical advice.

\section{LITERATURE CITED}

Adame K, Elorriaga-Verplancken FR, Beier E, AcevedoWhitehouse K, Pardo MA (2020) The demographic decline of a sea lion population followed multi-decadal sea surface warming. Sci Rep 10:10499

Australian Fisheries Management Authority (2015) Australian sea lion management strategy, southern and eastern scalefish and shark fishery (arrangements effective from 1 May 2013; Version 2.0-updated July 2015). https://www.afma.gov.au/sites/default/files/uploads/ 2014/03/Australian-Sea-Lion-Management-Strategy2015-v2.0-FINAL.pdf

Bates D, Maechler M, Bolker B, Walker S (2015) Fitting linear mixed-effects models using lme4. J Stat Softw 67: $1-48$

Baylis MM, Orben RA, Arnould JPY, Christiansen F, Hays GC, Staniland IJ (2015) Decline of sea lions. Bull Ecol Soc Am 96:635-638

* Berkson JM, DeMaster DP (1985) Use of pup counts in indexing population changes in pinnipeds. Can J Fish Aquat Sci 42:873-879

Boyd I, Wanless S, Camphuysen C (2006) Top predators in marine ecosystems: their role in monitoring and management. Cambridge University Press, Cambridge

* Campbell R, Holley D, Christianopoulos D, Caputi N, Gales N (2008a) Mitigation of incidental mortality of Australian sea lions in the west coast rock lobster fishery. Endang Species Res 5:345-358

* Campbell RA, Gales NJ, Lento GM, Baker CS (2008b) Islands in the sea: extreme female natal site fidelity in the Australian sea lion, Neophoca cinerea. Biol Lett 4: 139-142

CBD (Convention on Biological Diversity) (2020) Zero draft of the post-2020 global biodiversity framework. CBD/WG
2020/2/3. https://www.cbd.int/doc/c/efb0/1f84/a892b98 d2982a829962b6371/wg2020-02-03-en.pdf (accessed 11 Nov 2020)

Committee on Taxonomy (2020) List of marine mammal species and subspecies. Society for Marine Mammalogy. www.marinemammalscience.org/science-and-publica tions/list-marine-mammal-species-subspecies/ (accessed 21 Jan 2021)

*Dennis TE, Shaughnessy PD (1999) Seal survey in the Great Australian Bight region of Western Australia. Wildl Res 26:383-388

Department of Sustainability Environment Water Population and Communities (2013) Recovery plan for the Australian sea lion (Neophoca cinerea). Commonwealth of Australia, Canberra

Gales NJ (1990) Abundance of Australian sea lions Neophoca cinerea along the southern Australian coast, and related research. Report to the Western Australian Department of Conservation and Land Management, South Australian National Parks and Wildlife Service and the South Australian Wildlife Conservation Fund, Perth

Gales NJ, Costa DP (1997) The Australian sea lion: a review of an unusual life history. In: Hindell M, Kemper CM (eds) Marine mammal research in the Southern Hemisphere, Book 1. Surrey Beatty and Sons, Sydney, p 78-87

*Gales NJ, Shaughnessy PD, Dennis TE (1994) Distribution, abundance and breeding cycle of the Australian sea lion, Neophoca cinerea (Mammalia: Pinnipedia). J Zool 234: 353-370

Goldsworthy SD (2015) Australian sea lion. Neophoca cinerea. The IUCN Red List of Threatened Species. Version 2015.2. e.T14549A45228341. https://dx.doi.org/10.2305/ IUCN.UK.2015-2.RLTS.T14549A45228341.en (accessed 11 Nov 2020)

Goldsworthy S, Gales N (2008) Neophoca cinerea. The IUCN Red List of Threatened Species. Version 2008: e. T14549A4443172. https://www.iucnredlist.org/species/ 14549/4443172 (accessed 11 Nov 2020).

Goldsworthy SD, Page B (2007) A risk-assessment approach to evaluating the significance of seal bycatch in two Australian fisheries. Biol Conserv 139:269-285

Goldsworthy SD, Bulman C, He X, Larcombe J, Littnan C (2003) Trophic interactions between marine mammals and Australian fisheries: an ecosystem approach. In: Gales NJ, Hindell M, Kirkwood R (eds) Marine mammals and humans: fisheries, tourism and management. CSIRO Publications, Collingwood, p 62-99

*Goldsworthy SD, Shaughnessy PD, Page B, Dennis TE and others (2007) Developing population monitoring protocols for Australian sea lions. Report for the Department of the Environment and Water Resources, July 2007. SARDI Aquatic Sciences Publication Number F2007/000554. SARDI Research Report Series No. 219. South Australian Research and Development Institute, Adelaide. https:// www.pir.sa.gov.au/_data/assets/pdf_file/0005/231629/ No_219_Developing_population_monitoring_protocols_ ASL_-DEH.pdf

KGoldsworthy SD, Shaughnessy PD, Page B, Lowther A, Bradshaw CJA (2008) Developing population monitoring protocols for Australian sea lions: enhancing large and small colony survey methodology. Final Report to the Australian Centre for Applied Marine Mammal Science (ACAMMS), Department of Environment, Water, Her- 
itage and Arts. SARDI Aquatic Sciences Publication No. F2008/000633-1. SARDI Research Report Series No. 297. https://pir.sa.gov.au/_data/assets/pdf_file/0003/231690/ No_297_Developing_population_monitoring_protocols_ for_Australian_sea_lions_enhancing_large_and_small_ colony....pdf

Goldsworthy SD, McKenzie J, Shaughnessy PD, McIntosh RR, Page B, Campbell R (2009a) An update of the report: Understanding the impediments to the growth of Australian sea lion populations. Report to the Department of the Environment, Water, Heritage and the Arts, . SARDI Research Report series No. 356. https://pir.sa.gov.au/ _data/assets/pdf_file/0009/231795/No_356_Update_to_ the_report_ASL_impediments_to_recovery.pdf

Goldsworthy SD, Page B, Lowther A, Shaughnessy PD and others (2009b) Developing population protocols to determine the abundance of Australian sea lions at key subpopulations in South Australia. Final report to the Australian Marine Mammal Centre, Department of the Environment, Water, Heritage and the Arts. SARDI Aquatic Sciences Publication Number F2009/000161-1, SARDI Research Report Series No: 348. South Australian Research and Development Institute, Adelaide. https: //www.pir.sa.gov.au/_data/assets/pdf_file/0007/231883 /No_348_Developing_population_protocols_AMMC_AS L_population_monitoring_2008.pdf

Goldsworthy SD, Page B, Shaughnessy PD, Hamer D and others (2009c) Innovative solutions for aquaculture planning and management: addressing seal interactions in the finfish aquaculture industry. FRDC Project 2004/201 Final Report. SARDI Aquatic Sciences Publication Number F2008/000222-1, SARDI Research Report Series Number 288. South Australian Research and Development Institute, Adelaide. https://www.pir.sa.gov.au/research/pub lications/research_reports/research_reports_2009

*Goldsworthy SD, Page B, Shaughnessy PD, Linnane A (2010) Mitigating seal interactions in the SRLF and the gillnet sector SESSF in South Australia. Final report to the Fisheries Research and Development Corporation. SARDI Publication No. F2009/000613-1. SARDI Research Report Series No. 405. South Australian Research and Development Institute, Adelaide. https://pir.sa.gov. au/_data/assets/pdf_file/0013/232006/No_405_ Mitigating_Seal_Interactions_in_the_SRLF_and_the Gillnet_Sector_SESSF_in_SA.pdf

Goldsworthy SD, Page B, Lowther AD, Shaughnessy PD (2012) Maintaining the monitoring of pup production at key Australian sea lion colonies in South Australia (2010/11). Final Report to the Australian Marine Mammal Centre. SARDI Publication No. F2010/000665-2. SARDI Research Report Series No. 601. South Australian Research and Development Institute, Adelaide. https://pir.sa. gov.au/_data/assets/pdf_file/0015/232233/Maintaining _the_monitoring_of_pup_production_at_key_Australian_ sea_lion_colonies_in_South_Australia_2010_11._Final_ report_to_the_Australian_Marine_Mammal_Centre.pdf

Goldsworthy SD, Mackay AI, Shaughnessy PD, Bailleul F, McMahon CR (2014) Maintaining the monitoring of pup production at key Australian sea lion colonies in South Australia (2013/14). Final Report to the Australian Marine Mammal Centre. SARDI Publication No. F2010/000665-4. SARDI Research Report Series No. 818. South Australian Research and Development Institute, Adelaide. https:// pir.sa.gov.au/_data/assets/pdf_file/0011/239987/ASL_ Pup_Production_Report_-_FINAL.pdf
Goldsworthy SD, Mackay AI, Shaughnessy PD, Bailleul F, Holman D (2015) Maintaining the monitoring of pup production at key Australian sea lion colonies in South Australia (2014/15). Final Report to the Australian Marine Mammal Centre. SARDI Publication No. F2010/000665-5. SARDI Research Report Series No. 871. South Australian Research and Development Institute, Adelaide. https:// pir.sa.gov.au/_data/assets/pdf_file/0003/266745/ Maintaining_the_monitoring_of_pup_production_at_key_ Australian_sea_lion_colonies_in_South_Australia_2014_ 15._Final_Report_to_the_Australian_Marine_Mammal_ Centre.pdf

Goldsworthy SD, Shaughnessy PD, Smart J, Mackay A and others (2019) Monitoring of Seal Bay and other pinniped populations on Kangaroo Island: 2017/2018. Report to the Department for Environment and Water. SARDI Publication No. F2014/000322-5. SARDI Research Report Series No. 1018. South Australian Research and Development Institute, Adelaide. https://www.pir.sa.gov.au/ __data/assets/pdf_file/0005/347972/Monitoring_of_Seal _Bay_and_other_pinniped_populations_on_Kangaroo_ Island_20172018.pdf

*Goldsworthy SD, Hodgson J, Holman D (2020) Australian sea lion investigations: 2018-19. Report to the Department for Environment and Water. SARDI Publication No. F2020/ 000052-1. SARDI Research Report Series No. 1051. South Australian Research and Development Institute, Adelaide. https://pir.sa.gov.au/_data/assets/pdf_file/0004/358285/ Australian_sea_lion_investigations_2018-19.pdf

*Hamer DJ, Goldsworthy SD, Costa DP, Fowler SL, Page B, Sumner MD (2013) The endangered Australian sea lion extensively overlaps with and regularly becomes bycatch in demersal shark gill-nets in South Australian shelf waters. Biol Conserv 157:386-400

*Harwood J, Prime JH (1978) Some factors affecting size of British grey seal populations. J Appl Ecol 15:401-411

* Hazen EL, Abrahms B, Brodie S, Carroll G and others (2019) Marine top predators as climate and ecosystem sentinels. Front Ecol Environ 17:565-574

* ${ }^{*}$ IUCN Standards and Petitions Committee (2019) Guidelines for Using the IUCN Red List Categories and Criteria. Version 14. https://www.iucnredlist.org/resources/ redlistguidelines

Kirkwood R, Goldsworthy S (2013) Fur seals and sea lions. CSIRO Publishing, Collingwood

Kovacs KM, Aguilar A, Aurioles D, Burkanov V and others (2012) Global threats to pinnipeds. Mar Mamm Sci 28: 414-436

* Leaders' Pledge for Nature (2020) https://www.leaderspledge fornature.org/Leaders_Pledge_for_Nature_27.09.20.pdf (accessed 11 Nov 2020)

* Ling JK (1999) Exploitation of fur seals and sea lions from Australian, New Zealand and adjacent subantarctic islands during the eighteenth, nineteenth and twentieth centuries. Aust Zool 31:323-350

*Lowther AD, Goldsworthy SD (2011a) Detecting alternate foraging ecotypes in Australian sea lion (Neophoca cinerea) colonies using stable isotope analysis. Mar Mamm Sci 27:567-586

KLowther AD, Goldsworthy SD (2011b) Maternal strategies of the Australian sea lion (Neophoca cinerea) at Dangerous Reef, South Australia. Aust J Zool 59:54-62

Kowther AD, Harcourt RG, Goldsworthy SD, Stow A (2012) Population structure of adult female Australian sea lions is driven by fine scale foraging site fidelity. Anim Behav 83:691-701 
Mackay AI, Goldsworthy SD (2017) Experimental field trials to test if alternative sea lion excluder devices (SLEDs) adequately prevent Australian sea lions from entering rock lobster pots. Report to the Fisheries Research and Development Corporation, FRDC Project No. 2016-055. https:// pir.sa.gov.au/_data/assets/pdf_file/0016/300058/FRDC_ Sea_Lion_Lobster_Pot_Report_-_FINAL.PDF

Marcus AD, Higgins DP, Gray R (2014) Epidemiology of hookworm (Uncinaria sanguinis) infection in free-ranging Australian sea lion (Neophoca cinerea) pups. Parasitol Res 113:3341-3353

Marcus AD, Higgins DP, Gray R (2015) Health assessment of free-ranging endangered Australian sea lion (Neophoca cinerea) pups: effect of haematophagous parasites on haematological parameters. Comp Biochem Physiol A Mol Integr Physiol 184:132-143

*Page B, McKenzie J, McIntosh R, Baylis A and others (2004) Entanglement of Australian sea lions and New Zealand fur seals in lost fishing gear and other marine debris before and after Government and industry attempts to reduce the problem. Mar Pollut Bull 49:33-42

* Pitcher B (2018) Australian Sea Lion Monitoring Framework: background document. Prepared for the Department of the Environment, March 2018. https://www. environment.gov.au/system/files/resources/137e80a170c7-4311-ba02-dcd61524e9f6/files/australian-sea-lionmonitoring-framework-background-document-2018.pdf

R Core Team (2017) R: a language and environment for statistical computing. R Foundation for Statistical Computing, Vienna

Shaughnessy PD, Dennis TE, Seager PG (2005) Status of Australian sea lions, Neophoca cinerea, and New Zealand fur seals, Arctocephalus forsteri, on Eyre Peninsula and the Far West Coast of South Australia. Wildl Res 32:85-101

Shaughnessy PD, McIntosh RR, Goldsworthy SD, Dennis TE, Berris M (2006) Trends in abundance of Australian sea

Editorial responsibility: B. Louise Chilvers, Palmerston North, New Zealand

Reviewed by: 2 anonymous referees lions, Neophoca cinerea, at Seal Bay, Kangaroo Island, South Australia. In: Trites AW, Atkinson SK, DeMaster DP, Fritz LW, Gelatt TS, Rea LD, Wynne KM (eds) Sea lions of the world. Alaska Sea Grant College Program, Anchorage, AK, p 325-351

* Shaughnessy PD, Goldsworthy SD, Hamer DJ, Page B, McIntosh RR (2011) Australian sea lions Neophoca cinerea at colonies in South Australia: distribution and abundance, 2004 to 2008. Endang Species Res 13:87-98

Stuart JL (2018) The cruise of the Jane and Emma. In: Warneke RM (ed) Three colonial adventures. Part 3. Edition Renard, Melbourne, p 1-77

* Thompson D, Strange I, Riddy M, Duck CD (2005) The size and status of the population of southern sea lions Otaria flavescens in the Falkland Islands. Biol Conserv 121: 357-367

Threatened Species Scientific Committee (2020) Conservation advice. Neophoca cinerea, Australian sea lion. Department of Agriculture, Water and the Environment, Canberra. www.environment.gov.au/biodiversity/threatened/ species/pubs/22-conservation-advice-23122020.pdf (accessed 21 Jan 2021)

UN (2019) The sustainable development goals report 2019. https://unstats.un.org/sdgs/report/2019/ (accessed 11 Nov 2020).

*van Ruth PD, Ganf GG, Ward TM (2010) Hot-spots of primary productivity: an alternative interpretation to conventional upwelling models. Estuar Coast Shelf Sci 90: 142-158

Warneke RM (1982) The distribution and abundance of seals in the Australasian region, with summaries of biology and current research. Mammals in the seas, Book 4. FAO Fisheries Series No. 5. FAO, Rome

Woinarski JCZ, Burbidge AA, Harrison PL (2014) The action plan for Australian mammals 2012. CSIRO Publishing, Collingwood

Submitted: November 18, 2020

Accepted: February 8, 2021

Proofs received from author(s): April 19, 2021 